Arq. Bras. Med. Vet. Zootec., v.67, n.5, p.1381-1389, 2015

\title{
Produção de leite e emissões de metano na região do Corede, RS
}

[Milk production and methane emissions in the region of Corede, $R S$ ]

\author{
T.V.A. Martins-Costa
}

Universidade de Passo Fundo - Passo Fundo, RS

\begin{abstract}
RESUMO
O presente artigo tem como objetivo analisar a produção de leite na região do Corede, com foco nas emissões de gases efeito estufa como uma externalidade negativa dessa importante atividade econômica. Para as estimativas de emissões, utilizou-se a metodologia Tier 1 proposta pelo IPCC. As emissões passaram de 1,0 gigagrama em 1974 para 8,64 gigagramas de CH4 em 2011, o que representa um acréscimo de 767\% nas emissões estimadas para o início do período de análise. Em termos de taxa de crescimento geométrica, as emissões cresceram a uma taxa de $6,0 \%$ ao ano. No entanto, se for considerada a emissão média de metano por litro de leite produzido, pode-se observar que ela reduziu significativamente de valor durante o período analisado, passando de 58 gramas de CH4 por litro de leite produzido em 1974 para 24 gramas em 2011, ou seja, as emissões de metano por litro de leite se reduziram pela metade, evidenciando que o ganho de produtividade permite uma redução das emissões, desde que acompanhado por uma redução do rebanho e de estratégias de gestão que reduzam as emissões.
\end{abstract}

Palavras-chave: pecuária leiteira, emissões de metano, Corede, externalidades

\begin{abstract}
The article aims to analyze milk production in the region COREDE focusing on emissions of greenhouse gases as a negative externality of this important economic activity. For emission estimates we used the Tier 1 methodology proposed by the IPCC. Emissions increased from 1.0 in 1974 to 8.64 gigagrams CH4 in 2011, representing an increase of $767 \%$ on an estimate of the beginning of the analysis period emissions. In terms of the rate of geometric growth, emissions increased at a rate of $6.0 \%$ per year. However, if we consider the average methane emission per liter of milk produced, we can see that it reduced significantly in value during the analysis period, from 58 grams of CH4 per liter of milk produced in 1974 to 24 grams in 2011, meaning that methane emissions per liter of milk are reduced by half, showing that the productivity gain allows a reduction in emissions, since it is followed by a herd reduction and management strategies that reduce emissions.
\end{abstract}

Keywords: Dairy Cattle, Methane, COREDE, externalities

\section{INTRODUÇÃO}

A pecuária de leite brasileira, assim como a de corte, apresenta diversas formas de produção e de organização da propriedade, que variam conforme a região do país e o tipo de produtor. Assim, coexistem no Brasil tanto sistemas de produção voltados exclusivamente para o mercado e ligados às lógicas produtivas e comerciais de cadeias produtivas consolidadas quanto sistemas dedicados ao autoconsumo, cujo excedente é colocado em mercados locais. As diferenças regionais, técnicas e socioeconômicas determinam diferentes arranjos produtivos, os quais conduzem a formas diferenciadas de produção e de relacionamento com o mercado, formando, assim, bacias produtoras de leite com suas próprias especificidades.

Os debates atuais sobre o futuro da pecuária, com particular incidência sobre as interações entre sistema de pecuária e desenvolvimento local, estão evoluindo em torno de dois temas:

- o seu impacto sobre o ambiente em nível global, como referido no relatório intitulado

Recebido em 25 de junho de 2014

Aceito em 10 de abril de 2015

E-mail: mcosta@upf.br 
Livestock's Long Shadow Steinfeld da FAO (2006) e

- seu papel na nutrição da população humana, o que está projetado para aumentar até 2050.

Nesta década, vários fatores promoveram mudanças na atividade leiteira do Sul do Brasil, entre eles pode-se destacar a existência de um forte atrativo devido à possibilidade de aumento da renda, quando comparada com a cultura de grãos. Assim, nas áreas de pastagens perenes, têm havido melhorias no manejo e na adubação e o aumento de conservação de forragens, em especial forrageiras de inverno. Além disso, a instalação de projetos de novas indústrias no Rio Grande do Sul tem colaborado para o aumento regional da produção de leite.

Os municípios da região do Conselho de Desenvolvimento da Região da Produção, doravante chamado simplesmente de Corede Produção, área de interesse desta pesquisa, caracterizam-se por serem de agricultura familiar empresarial, de um lado, e industrializada, de outro. Ou seja, em sua maioria, os agricultores dessa região são de estrutura familiar, especializados, capazes de gerar excedentes exportáveis voltados para a comercialização de sua produção para cadeias produtivas consolidadas. (A produção leiteira do Corede Produção que se insere neste cenário é composta pelos 21 municípios, a saber: Almirante Tamandaré do Sul; Camargo; Carazinho; Casca; Ciríaco; Coqueiros do Sul; Coxilha; David Canabarro; Ernestina; Gentil; Marau; Mato Castelhano; Muliterno; Nova Alvorada; Passo Fundo; Pontão; Santo Antônio do Palma; Santo Antônio do Planalto; São Domingos do Sul; Vanini e Vila Maria).

O aumento do efeito estufa e suas consequências a longo prazo sobre as mudanças climáticas suscitam preocupações crescentes em todos os países do mundo. Historicamente, a pecuária bovina está ligada ao desenvolvimento econômico de diversas regiões do Brasil. Com um rebanho bovino com mais de 200 milhões de cabeças, o país é o principal produtor comercial de bovinos no mundo, sendo a produção de carnes uma das principais atividades da agropecuária brasileira. Assim, a criação bovina é uma importante fonte de emissões dos GEEs do Brasil. O primeiro inventário brasileiro avalia o equivalente a 57 milhões de toneladas de carbono das emissões nacionais de metano ligadas às fermentações entéricas e aos dejetos animais do rebanho bovino (Lima et al., 2002).

No entanto, a tarefa de analisar a contribuição da pecuária bovina nas emissões de GEEs necessita da identificação dos contextos regionais em que ocorrem os diferentes sistemas de produção no Brasil. Assim, para se compararem diferentes sistemas produtivos, é necessário utilizar uma metodologia que permita quantificar as emissões de metano decorrentes tanto da fermentação entérica como do manejo dos resíduos em propriedades rurais. Além disso, tal metodologia deve permitir a coleta de dados que reflitam a realidade dos diferentes contextos produtivos. Dessa forma, é necessário avaliar as emissões e as oportunidades de redução de gases efeito estufa na pecuária de leite local.

Assim, este artigo tem como objetivo analisar a produção de leite na região do Corede, com foco nas emissões de gases efeito estufa como uma externalidade negativa dessa importante atividade econômica. Para tanto, em primeiro lugar, analisou-se, com base em dados secundários, a evolução do rebanho e da produção de leite da região. Em segundo lugar, foram feitas estimativas preliminares das emissões de metano por fermentação entérica ocasionadas pelas vacas ordenhadas, bem como foi realizada uma estimativa de emissões futuras com base no comportamento histórico das emissões. A seguir, realizou-se uma discussão dos resultados, com o intuito de levantar possibilidades viáveis de redução de emissões. Por último, foram apresentadas as principais conclusões.

\section{MATERIAL E MÉTODOS}

A metodologia para a estimativa das emissões de metano ( $\mathrm{CH} 4)$ oriundas das categorias animais requer todas as definições sobre as categorias de animais, populações anuais e estimativas de dieta alimentar. A metodologia utilizada para a estimação das emissões é baseada na metodologia apresentada pelo IPCC para a realização dos relatórios nacionais de emissões de GEEs. Essa é apresentada no IPCC Guidelines for National Greenhouse Gas Inventories: Reference Manual (1996) e no IPCC Good Practice Guidance and Uncertainty Management 
in National Greenhouse Gas Inventories (IPCC, 2001).

Conforme o IPCC (1996), o método para a estimativa das emissões de metano por fermentação entérica e por manejo de dejetos requer três passos básicos:

Passo 1: dividir a população de gado em subgrupos e caracterizar cada subgrupo. É recomendado que os peritos nacionais usem a média de dados de três anos de atividade se disponível. Para desenvolver estimativas precisas de emissões, o gado deve ser dividido em categorias de grupos relativamente homogêneas. Para cada categoria, um animal representativo é escolhido e caracterizado com a finalidade de calcular um fator de emissão. No mínimo, três categorias principais são recomendadas: gado adulto de leite, gado adulto de não leite e gado jovem;

Passo 2: Estimar os fatores de emissão de estimativa para cada subgrupo em termos de quilogramas de metano por animal por ano. São requeridos fatores de emissão separados para fermentação entérica e dejetos;

Passo 3: multiplicar o fator de emissão de subgrupo pelas respectivas populações para estimar a emissão do subgrupo. Após, somar as emissões calculadas. Isto pode ser executado em níveis variados de detalhe e complexidade. O IPCC apresenta as seguintes duas aproximações:

Tier 1: uma aproximação simplificada, que utiliza um fator de emissão previamente escolhido de estudos, considerando ser suficiente para a maioria dos tipos de animais, na maioria dos países;

Tier 2: uma aproximação mais complexa, que requer informação específica de cada país sobre as características do gado e as práticas de administração de dejeto. Esta é recomendada quando os dados são desenvolvidos e quando os valores defaut não correspondem bem ao gado do país e às condições de administração de esterco. Uma vez que as características de gado variam significativamente para cada país, é recomendado que países com grandes populações de gado considerem usar a Tier 2 para calcular as emissões de metano de gado e a administração do esterco de gado. Semelhantemente, para búfalo e suínos, cujas práticas de administração do estrume variam significativamente por país, é recomendado aos países com grandes populações desses animais usarem a Tier 2 para calcular emissões de metano oriundas do esterco desses animais.

Tabela 1. Coeficientes de emissão utilizados e respectivas fontes

\begin{tabular}{lcc}
\multicolumn{1}{c}{$\begin{array}{c}\text { Produtividade } \\
\text { litros de leite/ano }\end{array}$} & $\begin{array}{c}\text { Coeficiente } \\
\text { (kg Ch4/animal/ano) }\end{array}$ & Fonte \\
\hline Até 1.000 litros & 58 & IPCC \\
1001 até 2.000 litros & 62 & Lima,2002 \\
2.001 até 3000 litros & 90 & IPCC, 2013 \\
Acima de 3000 litros & 117 & Martins-Costa, 2008 \\
\hline
\end{tabular}

Fonte: Elaborado pelo autor.

O presente estudo adaptou a metodologia Tier 1 do IPCC para a escala da região do Corede. Posteriormente, pretende-se empregar a metodologia Tier 2 para os cálculos das emissões. Optou-se por utilizar fatores de emissões para cada nível de produtividade de leite. Os níveis de produtividade e os respectivos valores utilizados como coeficientes de emissões de metano são apresentados no Tab. 1.

Para análise da atividade leiteira na região do Corede, utilizaram-se os dados do Instituto
Brasileiro de Geografia e Estatística (IBGE), Pesquisa Pecuária Municipal para os anos de 1994 a 2011.

No presente estágio da pesquisa, não foi realizada uma análise estatística em relação aos diferentes resultados de emissões obtidos para cada município do Corede. Tal refinamento metodológico será apresentado em outros artigos à medida que se obtenham dados específicos dos diferentes sistemas de produção praticados na região. 


\section{RESULTADOS}

O efetivo do rebanho leiteiro da região do Corede cresceu substancialmente nas últimas quatro décadas. A dinâmica de ocupação do solo agrícola, caracterizada pela crescente integração de lavouras com pecuária, foi um dos fatores que possibilitaram ao agricultor- pecuarista diversificar a produção com a crescente participação do gado leiteiro. De fato, a taxa geométrica de crescimento do número de vacas ordenhadas foi de $4,3 \%$ ao ano desde a década de 70 , fato que elevou a participação do rebanho da região de $2 \%$ para $5,6 \%$ do total de vacas ordenhadas no Rio Grande do Sul. (Fig. 1).

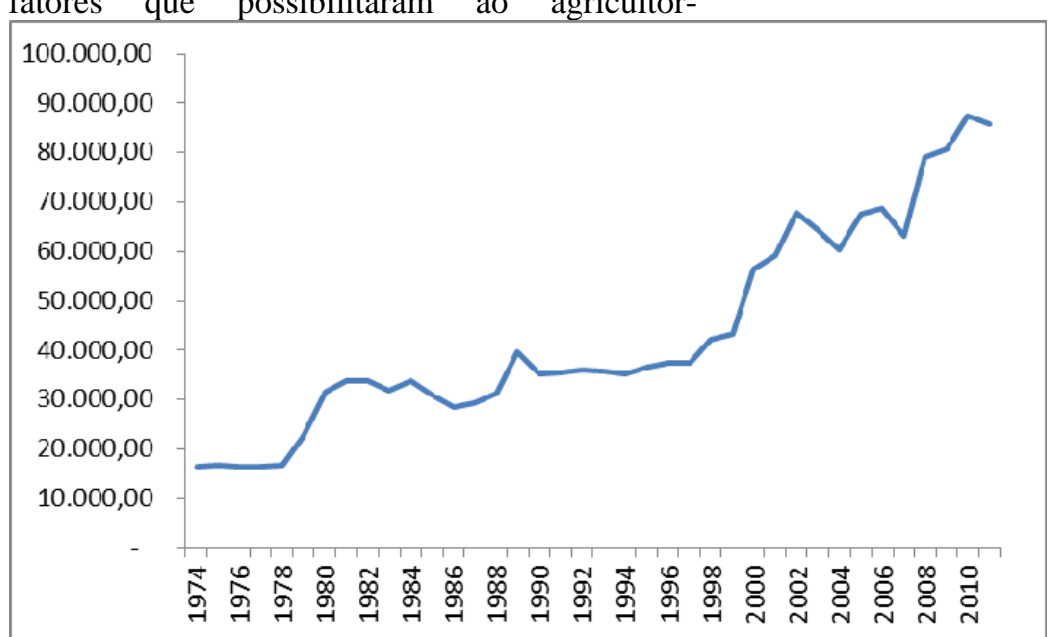

Figura 1. Evolução do número de vacas ordenhas na região do Corede: 1974 a 2011

Fonte: Elaborado pelo autor com base no IBGE, 2013.

Ao se observar a produção total de leite do Corede, verifica-se que ela também apresentou crescimento substancial ao longo das quatro décadas, com uma taxa de crescimento de $8,2 \%$ ao ano, valor cinco vezes superior ao da taxa de crescimento no número de vacas ordenhadas. Em 2011, a produção total de leite regional foi de 388 milhões de litros, o que se traduz numa média de 18,4 milhões de litros de leite produzidos por município e representa mais do que a média de leite produzida por município do Rio Grande do Sul (Fig. 2).

A produtividade média da região em 1974 era de 1.058 litros/vaca/ano ou 3,47 litros de leite/dia, considerando-se 305 dias de lactação.

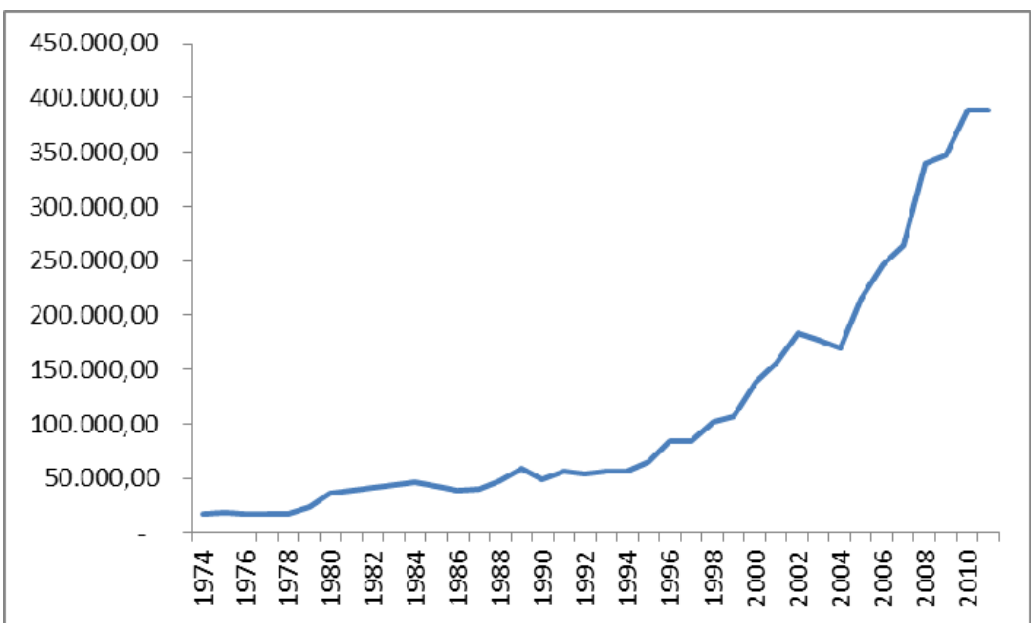

Figura 2. Evolução da produção de leite (mil litros) na região do Corede: 1974 a 2011 Fonte: Elaborado pelo autor com base no IBGE, 2013. 


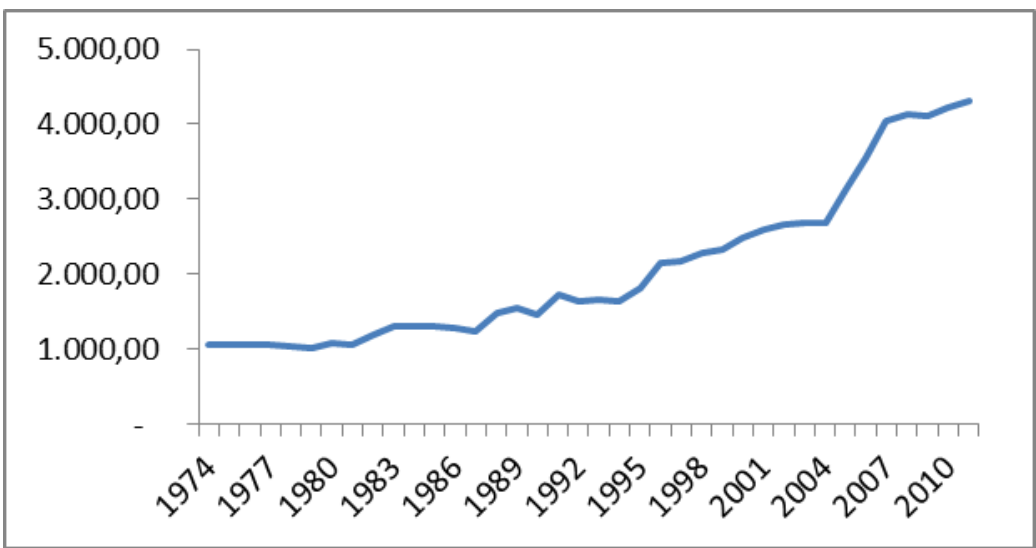

Figura 3. Evolução da produtividade média (litros/vaca/ano) por município do Corede: 1974 a 2011. Fonte: Elaborado pelo autor, com base no IBGE, 2013.

Em 2011, a produtividade elevou-se para 4.305 litros/vaca/ano ou 14,11 litros/vaca/dia. A taxa de crescimento da produtividade média da região foi de 3,7\% ao ano, valor superior ao incremento anual de $1,6 \%$ no número de vacas ordenhadas (Fig. 3).

A produtividade média dos municípios do Corede é superior à produtividade média do Rio Grande do Sul. Apenas dois municípios (Almirante Tamandaré e Coqueiros do Sul) apresentam produtividade inferior à média do estado (Fig. 4).
Com relação à produção de leite, os cinco maiores produtores da região são Marau, Casca, Passo Fundo, Vila Maria e Pontão. Em conjunto, esses municípios respondem por mais da metade da produção de leite do Corede, com destaque para o município de Casca, por ter a maior produtividade e o segundo maior rebanho de vacas leiteiras, fato que coloca o município na segunda posição no ranking da produção da região (51.592,00 mil litros). O município de Marau, que é o maior produtor de leite (55.200,00 mil), apresenta o maior rebanho, porém é apenas o nono colocado no ranking da produtividade.

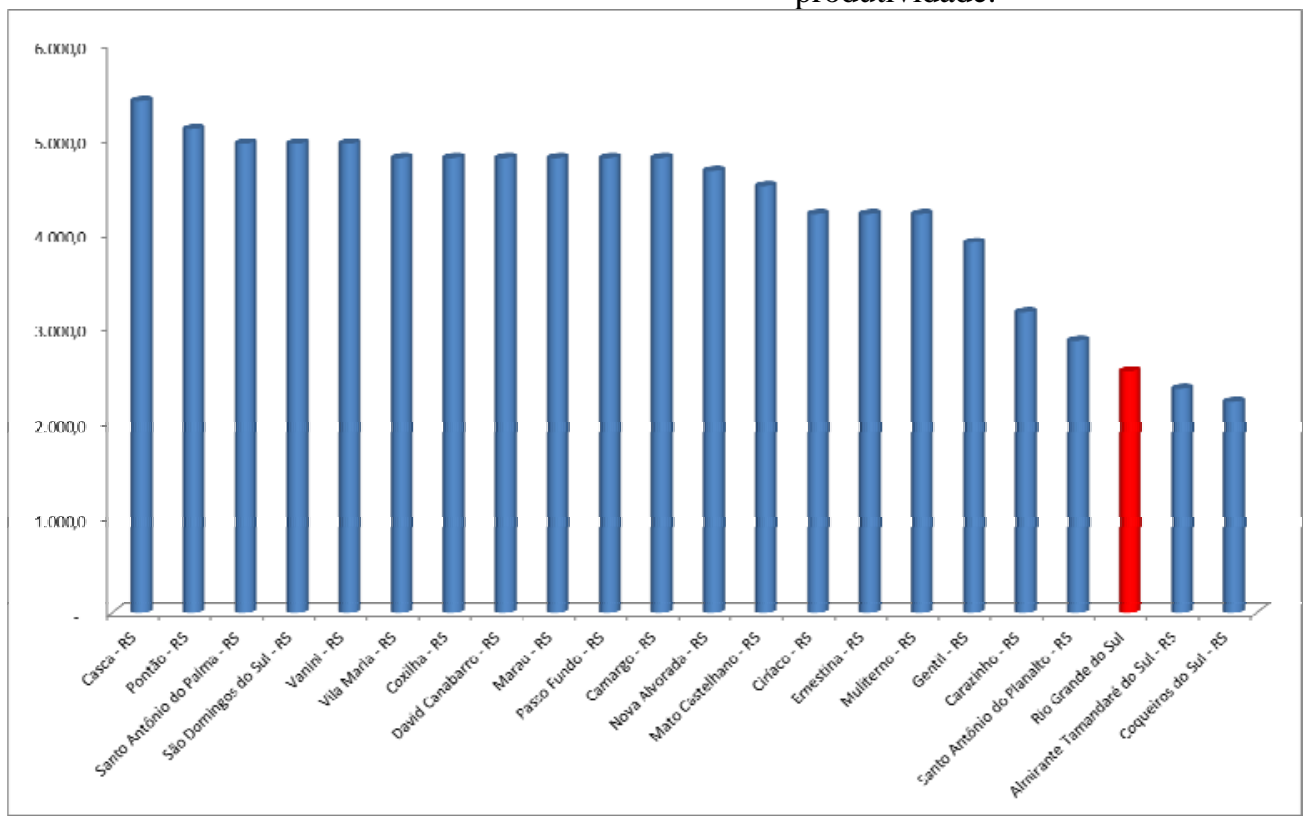

Figura 4. Ranking da produtividade média (litros/vaca/ano) por município do Corede e Rio Grande do Sul: 1974 a 2011.

Fonte: Elaborado pelo autor, com base no IBGE, 2013. 
Em suma, uma mudança significativa foi observada na produção de leite dos municípios que atualmente constituem o Corede. Nas últimas quatro décadas, o efetivo do rebanho aumentou 86\%, ou seja, praticamente quintuplicou o número de vacas ordenhadas. Por sua vez, a produtividade quadruplicou no mesmo período. O aumento expressivo no número de vacas ordenhadas, aliado ao significativo ganho de produtividade, elevou a produção de leite regional, especialmente nos últimos 10 anos. Assim, a produção atual é mais do que 20 vezes superior à obtida em meados da década de 70 .

É evidente que um aumento na produção de leite nessa magnitude se traduziu em melhorias econômicas para a região, dado o aumento no valor da produção. No entanto, num contexto de desenvolvimento sustentável, a melhoria da dimensão econômica deve se traduzir em melhorias sociais, acompanhadas da preservação das condições ambientais. A seguir, são apresentados os efeitos ambientais no que concerne às emissões de gases efeito estufa por fermentação entérica do gado de leite.

O crescimento do rebanho, aqui traduzido pelo número de vacas ordenhadas, e o aumento contínuo da produtividade do rebanho e da produção de leite se traduziram em crescentes emissões de metano ao longo das últimas quatro décadas.

A Fig. 5 ilustra a evolução das emissões de metano por fermentação entérica das vacas ordenhas na região do Corede, durante o período analisado. As emissões passaram de 1,0 gigagrama em 1974 para 8,64 gigagramas de $\mathrm{CH}_{4}$ em 2011, o que representa um acréscimo de $767 \%$ nas emissões estimadas para o início do período de análise. Em termos de taxa de crescimento geométrica, as emissões cresceram a uma taxa de 6,0\% ao ano. Além disso, observase, pela linha de tendência, um crescimento exponencial das emissões de metano por fermentação entérica ao longo do período analisado.

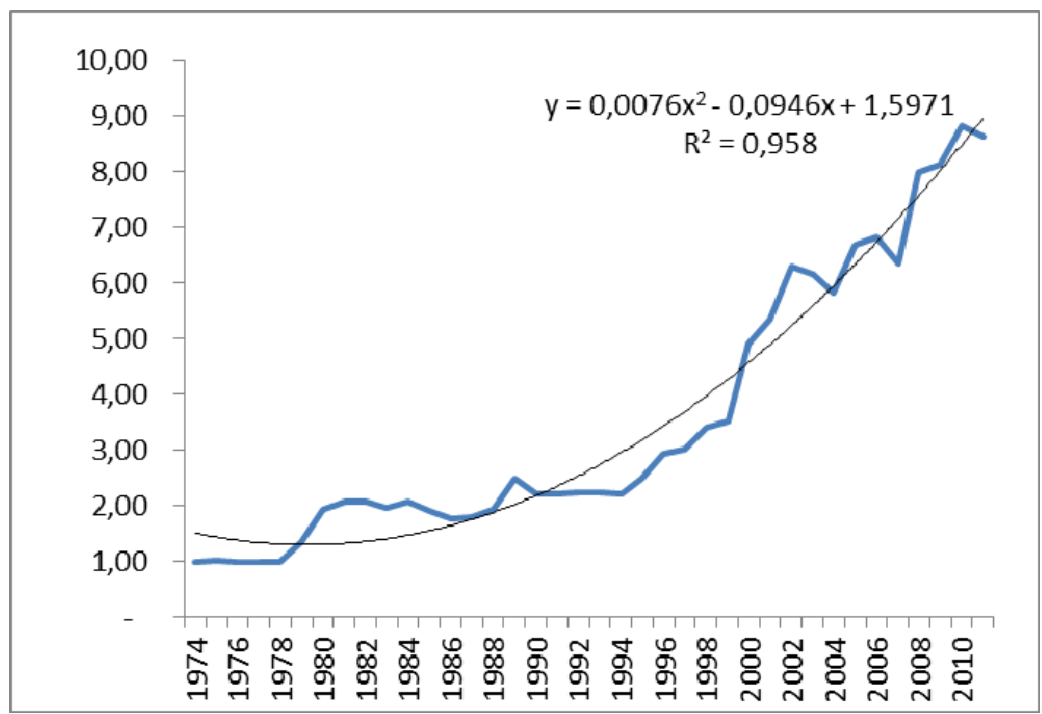

Figura 5. Evolução das emissões de metano por fermentação entérica de vacas ordenhadas do Corede, entre 1974 a 2011(Em gigagramas).

Fonte: Dados de pesquisa, 2013.

A Fig. 6 apresenta uma estimativa para as emissões futuras de metano do rebanho leiteiro para o ano de 2010. A estimativa foi obtida utilizando-se a equação de estimação da linha de tendência apresentada no Gráfico 5. Observa-se que, mantendo-se as condições históricas de crescimento, as emissões de metano para o ano de 2020 são estimadas em, aproximadamente, 14 gigagramas, ou seja, as emissões poderão crescer em $62 \%$ no final dessa década e dobrar de valor em aproximadamente 13 anos.

Com relação às emissões de metano por município do Corede, os cinco maiores 
produtores de leite da região, ou seja, Marau (1,17Gg), Casca (0,97Gg), Passo Fundo (0,80Gg), Vila Maria (0,68Gg) e Pontão $(0,59 \mathrm{Gg})$, são os que apresentam os maiores valores de emissão (Em conjunto, esses municípios respondem por mais da metade das emissões de metano do Corede).

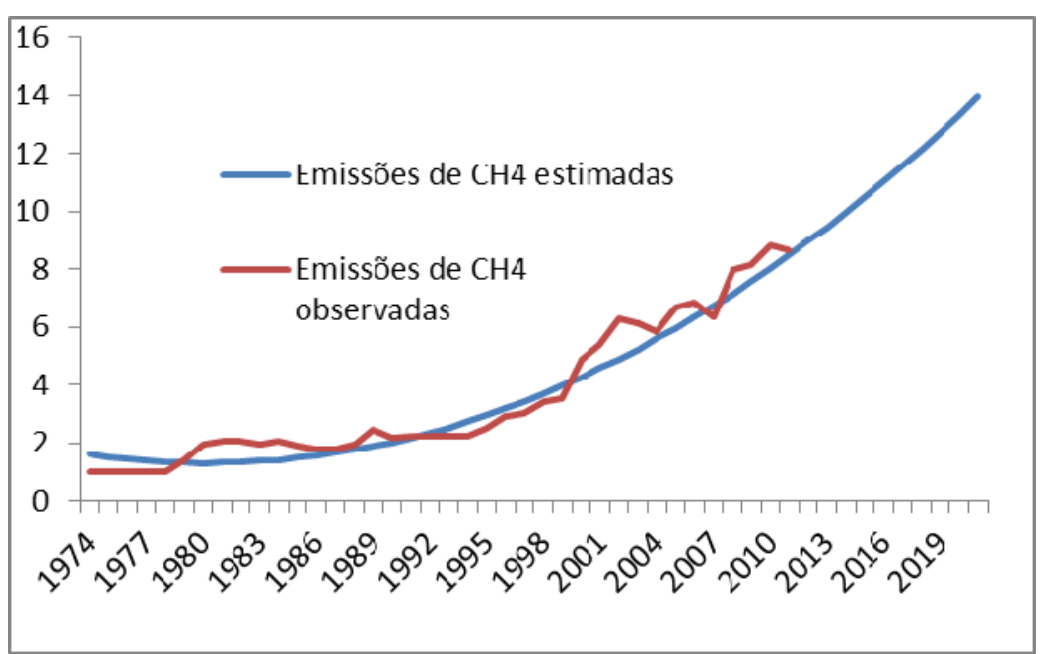

Figura 6. Estimativa das emissões de metano por fermentação entérica de vacas ordenhadas do Corede (Em gigagramas).

Fonte: Dados de pesquisa, 2013.

No entanto, se for considerada a emissão média de metano por litro de leite produzido, pode-se observar que ela reduziu significativamente de valor durante o período analisado, passando de 58 gramas de $\mathrm{CH}_{4}$ por litro de leite produzido em 1974 para 24 gramas em 2011, ou seja, as

emissões de metano por litro de leite se reduziram pela metade, evidenciando que o ganho de produtividade permite uma redução das emissões, desde que acompanhado por uma redução do rebanho (Fig. 7).

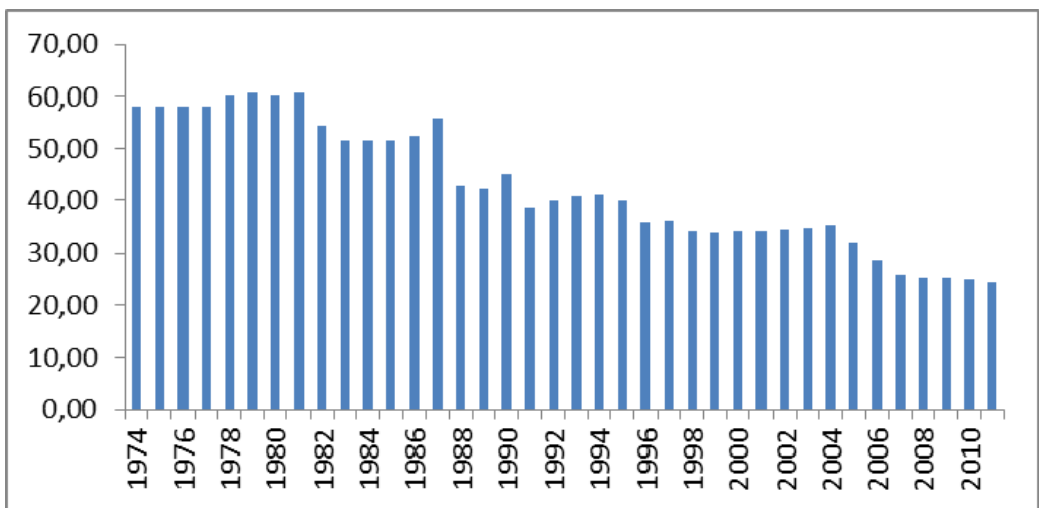

Figura 7. Estimativa das emissões médias de metano por fermentação entérica de vacas ordenhadas do Corede por litro de leite produzido ( Em gramas).

Fonte: Dados de pesquisa, 2013.

\section{DISCUSSÃO}

A maior parte das emissões de metano vem da fermentação entérica, resultado normal do processo digestivo dos animais ruminantes como os bovinos. (Crutzen, 1986) O metano produzido durante o processo representa, em parte, um uso improdutivo da energia contida na alimentação do gado. Assim, vários pesquisadores estão tentando identificar os meios de redução dessas emissões, assim como o sequestro de carbono nas pastagens (AEA, 1998; Boddey, 2004; Jones, 
2004; Leconte, 2002; Tarré, 2001). Os resultados mais promissores para essa redução são obtidos com o melhoramento da produtividade e da eficácia na produção. Isso permite reduzir as emissões não por animal, mas por unidade de produção (quilo de leite ou de carne). O caso de intensificação da criação bovina leiteira americana é, por vezes, destacado como tendo contribuído ao mesmo tempo para a redução das emissões antrópicas dos GEEs e para uma melhor competitividade do setor bovino (U.S. EPA, 2002). Outras consequências benéficas são destacadas, como a melhora da saúde animal, a estabilidade da produção e a redução das importações dos produtos animais em escala nacional (U.S.EPA, 2002).

Uma melhor gestão das pastagens, de práticas de suplementação alimentar, a substituição das forragens por alimentos contendo menos fibra, um controle sanitário adequado, uma gestão integrada dos dejetos animais, assim como as melhoras de performances genéticas dos animais são, do mesmo modo, as técnicas suscetíveis de crescimento da produtividade dos rebanhos e da redução das emissões ligadas à pecuária bovina (FAO, 2006). Trabalhos suplementares buscam desenvolver sistemas silvopastoris, introduzindo as árvores nas pastagens, de maneira a aumentar a produtividade da exploração. Outros trabalhos em curso sobre as biotecnologias permitem modificar o funcionamento do rúmen dos animais. Os resultados desses trabalhos poderão, todavia, ir de encontro aos problemas de aceitação pública (Ministère Des Affaires Éstrangères, 2001).

Em geral, essas técnicas reduzem em $60 \%$ a produção de metano por unidade de produto, com significativo ganho de produtividade, especialmente na produção leiteira. Além do ganho de produtividade, destacam-se outros benefícios, tais como: melhoria da sanidade animal, estabilidade da produção em nível de fazenda e redução da necessidade de importações de produtos animais ((U.S. EPA, 2002); Steinfeld, 2006).

Tanto ruminantes como não ruminantes produzem $\mathrm{CH} 4$, contudo os ruminantes são os maiores emissores, visto que são capazes de digerir a celulose pela presença de microrganismos em seu trato digestivo. A quantidade de $\mathrm{CH} 4$ resultante depende do tipo, da idade e do peso do animal, da qualidade e quantidade de alimento, e da energia consumida pelo animal. O CH4, também, é produzido pela decomposição de estrume sob condições anaeróbicas. Tais condições ocorrem sempre quando um grande grupo de animais é confinado, e, consequentemente, os dejetos são estocados, tipicamente, em grandes pilhas ou dispostos em lagos. Além disso, durante a armazenagem dos dejetos, parte do nitrogênio é convertida em N2O. Emissões de $\mathrm{N} 2 \mathrm{O}$ provenientes do manuseio dos dejetos antes que estes sejam incorporados ao solo são incluídas nessa categoria (Emissões de $\mathrm{N} 2 \mathrm{O}$ por dejetos incorporados no solo são consideradas emissões agrícolas do solo).

Existem diversas formas para se reduzirem as emissões de metano dos ruminantes. Entre elas, pode-se destacar: a redução do efetivo animal; a melhoria da eficiência da conversão alimentar pela otimização de dietas do rebanho; o incremento da produtividade animal por meio do uso de aditivos na alimentação ou na cria; e a melhoria da eficiência do rúmen mediante o uso de aditivos na alimentação (Bates, 2001).

Porém, como destaca Bates (2001), essas opções são novas e necessitam de maiores pesquisas e desenvolvimento que comprovem evidências conclusivas da possível redução e da avaliação de custos. Apenas a técnica do precursor de propianato apresenta dados sobre custos. Bates (2001) ainda destaca aumento da produtividade animal mediante o uso de aditivos como estratégia de redução das emissões de metano por fermentação entérica. A produtividade animal pode ser incrementada por meio de uma série de aditivos alimentares. Esta opção é líder na redução de emissões de metano somente se o total de leite ou carne for mantido constante. As possíveis opções para o aumento da produtividade são: uso de probióticos, ionóforos; antibióticos e halogênicos; e somatotropina bovina (SBT). A utilização de produtos químicos e antibióticos para aumentar a produtividade bovina tem apresentado um crescente descontentamento por parte dos consumidores. A União Europeia já baniu o uso de uma série de aditivos alimentares.

Enfim, a importância da emissão de metano pela fermentação entérica de bovinos e as possibilidades de redução dessas emissões num 
quadro de desenvolvimento sustentável ilustram quão premente é a necessidade de se desenvolverem pesquisas nessa área para que melhor se compreendam os impactos econômicos, sociais e ecológicos, tal é o caso da pecuária de leite na região do Corede.

\section{CONCLUSÕES}

A produção sustentável também passa pelas opções de redução de metano por fermentação entérica ocorrida pela melhoria da conversão alimentar e pela consequente melhoria da produtividade, o que pode levar ao aumento das emissões de metano por animal, mas as emissões de metano por unidade de leite ou de carne são reduzidas. Porém, essa opção somente reduzirá o total das emissões entéricas se a quantidade de produção de carne ou de leite for mantida constante, ou seja, acréscimos na produtividade devem levar ao decréscimo no número de animais. No caso da região do Corede, em termos de taxa de crescimento geométrica, as emissões cresceram ao longo do período analisado. No entanto, se for considerada a emissão média de metano por litro de leite produzido, pode-se observar que ela reduziu significativamente de valor, ou seja, as emissões de metano por litro de leite se reduziram pela metade, evidenciando que o ganho de produtividade permite uma redução das emissões, desde que acompanhado por uma redução do rebanho e por estratégias de gestão que reduzam as emissões.

\section{REFERÊNCIAS}

BATES, J. Economic evaluation of emission reductions of nitrous oxides and methane in agriculture in EU: bottom-up analysis. Abingdon: AEA Technology Environment, 2001.

BODDEY, R. M.; MACEDO, R.; TARRÉ, R.M. et. al. Nitrogen cycling in Brachiaria pastures: the key to understanding the process of pasture decline. Agric. Ecosyst. Environ., v.103 p.389-403, 2004. Disponível em: <http://www.sciencedirect.com/science/article/pii/ S016788090300447X>. Acessado em: 20 jun. 2004.

CRUTZEN, P. J.; ASELMANN I.; SEILER, W. Methane production by domestic animals, wild ruminats, other herbivorous fauna, and humans. Tellus B, v.38D, p.271-284, 1986.

IBGE. Pesquisa Pecuária Municipal. Sistema de dados agregados - SIDRA. Disponível em <http://www.ibge,go,br. Acessado em: 20 abr. 2014.
IPCC guidelines for national greenhouse gas inventories: reference manual. Cambridge: University Press, 1996. 297p.

IPCC Good practice guidance and uncertainty management in national greenhouse gas inventories. Chapter 4: Agriculture. Cambridge: University Press, 2001

JONES, S. K. Greenhouse gas emissions from a manage grassland. Global and Planetary Change, 2004. Disponível em: $<$ www.sciencedirect.com/ science/article/pii/S0921818104001973>. Acesso: 6 jul. 2004.

LECOMTE, Ph., BOVAL M., GUERIN H. et al. Carbone et élevage de ruminants. (2002) Comunication apresenté dans le Colloque international sur la gestion de la biomasse sur l'érosion et la séquestration du carbone. Montpellier.

LIMA, M. A.; PESSOA, M.C.P.Y.; LIGO, M.A.V. Emissões de metano da pecuária. Brasília MCT, 2002. Relatórios de referência Disponível em: $<$ http://www.forumclimabr.org.br/inventario.htm>.

Acessado em: 2002.

LIVESTOCK'S long shadow: environmental issues and options. Rome: FAO, 2006.

MARTINS-COSTA, T.V., Agripec: un modèle d`estimation des coûts economiques et des emissions de gaz à effet de serre dans le secteur de lélevage bovin brésilien. 2008. 347p. Tese (Doutorado) Institut des Sciences et Industries du Vivant et de L`environnement: AgroParisTech, Paris.

ANALYSE comparative des instruments économiques de mise en oeuvre des accords multilatéraux sur I'environnement pour les pays membres de la ZSP. Paris MINISTERE DES AFFAIRES ÉSTRANGERES: ETUDE, 2001.

OPTIONS to reduce methane emissions. [s.l.]: AEA Technology Environment, 1998. Final Report, AEAF 3773 Issue 3.

STEINFELD, H.; GERBER, P.; WASSENAAR, T. et.al. Livestock's long shadow: environmental issues and options. Rome: Food and Agriculture Organization of the Uniten Nations, 2006.

TARRÉ, R.; MACEDO, R.; CANTARUTTI, R.B. et. al. The effect of the presence of a forage legume on nitrogen and carbon levels in soils under Brachiaria pastures in the Atlantic forest region of the South Bahia, Brazil. Plant Soil, v.234, p.15-26, 2001.

U.S. EPA. Options for reducing methane emissions internationall.2002. Disponível em: http://www.epa.gov. Acesso: 15 ago 2002. 